\title{
Insulin-Like Growth Factor I and the Pathogenesis of Delirium: A Review of Current Evidence
}

\author{
Dimitrios Adamis ${ }^{1,2}$ and David Meagher ${ }^{3,4}$ \\ ${ }^{1}$ Research and Academic Institute of Athens, 27 Themistokleous Street and Akadimias, 10677 Athens, Greece \\ ${ }^{2}$ HSPR Department, Institute of Psychiatry, Kings College, Room HO.09, David Goldberg Building, de Crespigny Park, \\ London SE5 8AP, UK \\ ${ }^{3}$ Psychiatry Graduate Entry Medical School, University of Limerick, Castletroy, Limerick, Ireland \\ ${ }^{4}$ Department of Psychiatry, Midwestern Regional Hospital, Dooradoyle, Limerick, Ireland
}

Correspondence should be addressed to Dimitrios Adamis, dimaadamis@yahoo.com

Received 15 March 2011; Revised 26 April 2011; Accepted 12 May 2011

Academic Editor: James M. Harper

Copyright ( 2011 D. Adamis and D. Meagher. This is an open access article distributed under the Creative Commons Attribution License, which permits unrestricted use, distribution, and reproduction in any medium, provided the original work is properly cited.

Delirium is a frequent complication in medically ill elderly patients that is associated with serious adverse outcomes including increased mortality. Delirium risk is linked to older age, dementia, and illness that involves activation of inflammatory responses. IGF-I is increasingly postulated as a key link between environmental influences on body metabolism with a range of neuronal activities and has been described as the master regulator of the connection between brain and bodily well-being. The relationships between IGF-I and ageing, cognitive impairment and inflammatory illness further support a possible role in delirium pathogenesis. Five studies of IGF-I in delirium were identified by a systematic review. These conflicting findings, with three of the five studies indicating an association between IGF-1 and delirium occurrence, may relate to the considerable methodological differences in these studies. The relevance of IGF-I and related factors to delirium pathogenesis can be clarified by future studies which account for these issues and other confounding factors. Such work can inform therapeutic trials of IGF-I and/or growth hormone administration.

\section{Introduction}

Delirium is an etiologically diverse organic cerebral syndrome of acute onset (over hours to days) characterized by a fluctuating course that includes alterations in level of consciousness, psychomotor behavior, attention and cognition, as well as variable expression of various neuropsychiatric disturbances [1]. It is a frequent complication in elderly hospitalized patients, affecting around 30\% [2]. Despite this frequency, delirium is frequently misdiagnosed or missed, and considerable uncertainty remains regarding optimal management [3-5]. Delirium is associated with a range of adverse outcomes, including, longer hospital stays, greater healthcare costs, reduced subsequent functional independence, and increased mortality [6]. The pathophysiology of delirium has been understudied [5], and, in particular, it remains uncertain how such a wide range of potential etiologies, many of which involve pathology at peripheral body locations and without clear links to CNS function, can produce such a consistent complex neuropsychiatric picture that reflects generalized brain dysfunction. Central to understanding delirium is understanding mechanisms by which body and brain well-being are linked and, in particular, how brain responses to bodily homeostatic stress is mediated.

\section{Delirium and the Aging Process}

Advanced age is an independent risk factor for developing delirium with increasing risk corresponding to increasing agedness, for example [7-11]. Dementia is another important risk factor for delirium that is also age-related with a prevalence of $1 \%$ at the age of 60 that doubles with each additional five years of age [12]. Approximately 50\% of 
patients with delirium have comorbid dementia [13], and the presence of dementia increases the risk of delirium by fivefold $[11,14,15]$. Even mild cognitive decline increases the risk for delirium [16]. Patients with dementia are more vulnerable to delirium at lower levels of medical morbidity that nondemented ones. In addition, stroke confers an eightfold increase in the risk for delirium [17] with the incidence of delirium in stroke patients varying from $13 \%$ to $48 \%$ [18]. Similarly, increasing age is associated with greater burden of morbidity and diminished tolerance of medications with the number and type of medication implicated as a principal cause of delirium in 12 to $39 \%$ of cases $[19,20]$. In essence, almost any dysfunction or damage of the brain resulting from acute illness, trauma, sepsis, medication or, other insults can cause delirium [21].

It is increasingly recognized that the traditional concept of delirium as a transient reversible condition is not evidenced in many older patients [9, 22-24] for whom more persistent cognitive and functional impairments are common [21, 25]. The irreversibility of some clinical features $[9,26]$, the emerging evidence of a relationship with dementia [27, 28], and the poor prognosis independent of premorbid factors suggest that the pathophysiological processes that underpin the syndrome of delirium can also be associated with more permanent decline of cerebral function and may overlap with those of dementia. Delirium is a highly heterogeneous condition regarding causation with typically multiple contributing etiological factors in any single case and single-etiology delirium the exception rather than the rule [29]. Inevitably, a number of different mechanisms have been proposed to explain the pathophysiology of delirium:the effects of medication, direct neurotoxicity of the delirious state due to changes in inflammatory and glucocorticoid systems [21,30-32]. More recently, studies have focused on the possible role of alterations in hormones with neuroprotective properties such as insulin-like growth factor I (IGF-I).

\section{The Neurobiology of IGF-I}

Insulin-like growth factor I (IGF-I) is one of a family of peptides that have important regulatory roles in bodily growth and related metabolic functions, as well as a variety of brain functions. IGF-I has been postulated as particularly important within this family due to its unusually complex regulatory neurobiology whereby; (a) IGF-I can be produced by any cell type with the liver as the primary site of production for circulating IGF-I [33], (b) IGF-I receptors are found on nearly all body cell types, and most brain regions express IGF-I immunoreactivity and possess IGF-I binding sites [34], (c) serum levels are extremely high and crucially linked to a range of CNS functions, (d) it is regulated by a the complex interplay of multiple binding proteins (IGFBPs), and (e) IGF-I unilaterally stimulates other growth factors many of which act downstream to IGF-I such that it appears to be a final common pathway for protein networks [35].

IGF-I receptors are highly expressed in the cells that constitute the blood-brain barrier and, in addition to regulating the integrity of this barrier, provide the route by which serum IGF-I accesses the brain. This well developed linkage mechanism between brain and peripheral activity of this key regulator of body metabolism, and CNS functional integrity has stimulated studies that explore the role of IGF-I in mediating the neuroprotective effects of activities such as exercise and increasingly highlight how interactions between IGF-I and other key metabolic regulators such as insulin allow for the brain and body to coordinate responses to environmental challenges. IGF-I regulates carbohydrate, fat, and protein metabolism, and serum levels are increased by increasing muscle mass by exercise [36]. This increase in serum IGF-I is communicated to the CNS which can then adapt with better motor coordination and enhanced CNScontrolled anabolic activity. Interestingly, evidence has indicated a protective effect of exercise upon risk for cognitive disturbance including delirium [37].

IGF-I is produced locally within the brain but in much greater quantities peripherally, especially in the liver. CNSproduced IGF-I has important recognized roles during CNS development and in adults in response to brain injury, but serum IGF-I is crucial to a wide variety of functions within the adult brain. These include promoting development, neuronal excitability, myelin sheath synthesis, blood vessel growth, neuronal survival, proliferation, differentiation, and synaptogenesis [38, 39], as well as facilitating cerebral glucose transport and metabolism. IGF-I promotes neuronal plasticity and it is this influence upon the cellular substrate of cognition that is thought to underpin the relationship between IGF-I metabolism and cognitive function noted with normal ageing, dementia, and delirium. It is a universal cytoprotectant, with neurotrophic actions that maintain neuronal functionality and contribute to the cellular mechanisms that provide the so-called "cognitive reserve" which is so important in determining predisposition towards cognitive failure in the face of precipitating physical insults. In the case of delirium, this has been traditionally referred to as "delirium readiness" and demonstrated in widely accepted risk factor models for delirium [40, 41].

IGF-I stimulates proliferation and survival of many cell types and is considered a universal cytoprotectant. It protects against free radical damage and apoptosis [34, 42]. However, this protective effect also applies to malignant cells and underpins the association between IGF-I and breast cancer and other tumors $[43,44]$. In chronic inflammation an interaction between IGF-I and other cytokines (especially IL6) has been suggested [45]. An interaction between cytokines and IGF-I in acute inflammation or sepsis and a reduction of IGF-I directly or indirectly thought TNF- $\alpha$ and/or IL- $1 \beta$ has been reported $[46,47]$.

\section{IGF-I and Ageing Processes}

Disturbed IGF-I function is found in progeria syndrome [48], and reduced IGF-I signaling in knockout mice strains is associated with reduced lifespan [49]. Aging is associated with a decrease in serum levels of IGF-I [50-53], while the IGF-I/IGFBP-3 (insulin-like growth factor binding protein) molar ratio is increased $[54,55]$. Despite some discrepancies in the levels of IGF-I in centenarians, for example [56, 57], 
most investigators agree that there is a decline of IGF-I levels with aging, but a clear explanation is lacking [58]. Suggested possibilities include reduced physical activity in the elderly [59], decreased muscle volume and increased body fat [60], poor nutritional status [61], or low levels of growth hormone (GH) (in men) [62].

A decline in IGF-I has been linked with decline in mobility in elderly women [63], and the combined effect of low IGF-I and high IL-6 predicted mortality and disability in a cohort of community-dwelling women [50]. Similarly, the Framingham Heart Study [64] identified that low IGFI (as well as IL-6 and TNF- $\alpha$ ) is associated with allcause mortality. However, other work has not replicated this finding [65] where high IGF-I levels were associated with increased all-cause mortality in elderly population. In contrast, two more studies reported no relationship between IGF-I levels and all-cause mortality [66, 67].

Other studies have investigated the relation of IGF-I with cognitive impairment and dementia. IGF-I gene deletion in humans is associated with mental retardation, microcephaly, and deafness [68], while knockout IGF-I mice have decreased brain size, disturbed glucose metabolism [69], and loss of hippocampal granule neurons [70]. In clinical settings, normalization of cognitive function is associated with normalization of IGF-I levels in young adults [71] and older patients [72] with growth hormone $(\mathrm{GH})$ deficiency in replacement therapy. Serum IGF-I levels correlate positively with cognitive performance in studies of healthy elderly subjects $[56,73,74]$. Studies in patients with Alzheimer's disease have been less consistent; reduced plasma levels of IGF-I in plasma were found in patients with familial $\mathrm{AD}$, carriers of the Swedish APP/670/671 mutation, when compared with controls from the same family without AD [75], while reduced IGF-I levels were found by Murialdo et al. [76] in AD patients compared to controls, and the IGFI levels were inversely correlated with cognitive impairment. In contrast, IGF-I levels were unaltered or increased in other studies of dementia patients [77-79]. IGF-I modulates many aspects of beta-amyloid physiology, including synthesis, cellular uptake, clearance, and degradation [80-82], can protect and rescue neurons against potential neuronal death induced by $\beta$-amyloid [42] and can modulate acetylcholine release in hippocampal slices in vitro [83]. Moreover, administration of IGF-I induces neurogenesis and increased progenitor cell proliferation in the adult rat hippocampus [84, 85]. Thus, it has been proposed that IGF-I may have a role in the treatment of $\mathrm{AD}[86,87]$.

The role of IGF-I in ageing and disease is under debate. Reduced levels of IGF-I are linked to reduced cancer risk and thus prolonging life [88], but conversely, low levels of IGF-I are associated with increased risk for age-related conditions like cognitive loss, dementia, frailty, tissue atrophy, and vascular dysfunction. This apparent contradiction in roles has not yet been resolved, perhaps because the many complex biological actions of IGF-I involve different pathways and other molecules.

Finally, interactions between IGF-I and key neurotransmitter systems implicated in delirium pathogenesis have been observed and include IGF-I's potential to increase choline acetyltransferase (CAT) levels, to prevent the loss of CAT activity, to modulate acetylcholine release, and to promote catecholaminergic and dopaminergic enzyme activities [34]. IGF-I has neurotrophic effects on dopaminergic neurons in vivo [89], and the administration of IGF-I in combination with other neurotrophic factors prior to transplantation of dopaminergic neurons in rats was found to prevent apoptosis and neuronal death [90]. More recently, it has been observed that the N-terminal tripeptide of IGF-I (GPE) is neuroprotective in dopaminergic neurons $[36,91$, 92].

It seems from the above that IGF-I has close links with cholinergic and dopaminergic systems which are emphasised as the key neurotransmitters in prevailing neurochemical models of delirium [93, 94]. IGF-I also has an important relationship with proinflammatory cytokines $[32,95]$ that are elevated in acute illnesses that are associated with delirium.

Given that delirium is associated with older age and dementia and IGF-I has important neurotrophic functions in the brain and its involvement in the ageing process, IGF-I has been a potential candidate for investigation in delirium. The aims of the present paper are (a) to review evidence from studies that have examined the relation of IGF-I and delirium, (b) to discuss the possible pathophysiological relationships between IGF-I and delirium (c) to discuss the discrepancies between the studies and their relevance to methodological differences, and (d) to recommend approaches to clarifying the role of IGF-I in delirium pathogenesis.

\section{Studies of IGF-I in Delirium}

5.1. Search Method for Relevant Studies. MEDLINE, EMBASE, and Scopus databases were searched using the keywords "delirium" or "acute confusion" combined with the keywords "Insulin-like growth factor I" or "Sulfation factor" or "Somatomedin- $C$ ". In addition, this was supplemented by a manual search of references from relevant papers. No limits in language or year of publication were used.

5.2. Presentations of the Studies. Five relevant research papers were retrieved (see Table 1). Wilson et al. [96] measured baseline serum levels of IGF-I in a cohort of one hundred acutely ill medical inpatients without delirium. Twelve patients developed incident delirium during the follow-up. Low IGF-I levels on admission were identified as a risk factor for the development of delirium (OR: 0.822, CI: 0.69, $0.97, P=.027)$. Adamis et al. [30] examined serum IGF-I levels in elderly medical inpatients with prevalent delirium at admission. They found that patients with delirium had significantly lower levels of serum IGF-I compared to controls. In addition, incorporating a regression model, they found that low IGF-I levels, female gender, and lack of APOE epsilon 4 allele were predictors of recovery from delirium in $76.5 \%$ of cases, with a sensitivity of 0.77 and specificity of 0.75 . 
TABLE 1: Studies of IGF-I in delirium.

\begin{tabular}{|c|c|c|c|c|c|c|c|}
\hline Authors & Settings & Design & $n$ & $\begin{array}{c}\text { Timing of IGF-I } \\
\text { measurement }\end{array}$ & Age (mean, sd) & $\begin{array}{c}\text { Baseline } \\
\text { cognitive status }\end{array}$ & Findings \\
\hline Wilson et al. [96] & Medical & Cohort & 12 & Baseline & $84.5,4.2$ & ${ }^{*} \mathrm{MCI}+$ normal & $\begin{array}{c}\text { Low IGF-I risk } \\
\text { for incident } \\
\text { delirium }\end{array}$ \\
\hline Adamis et al. [30] & Medical & Cross-sectional & 22 & Baseline & $84.6,6.5$ & $\begin{array}{c}50 \% \text { with } \\
\text { dementia }+ \\
\mathrm{MCI}+\text { normal }\end{array}$ & $\begin{array}{l}\text { Association of } \\
\text { IGF-I and } \\
\text { prevalence } \\
\text { delirium }\end{array}$ \\
\hline Lemstra et al. [97] & Orthopaedic & Case Control & 18 & Baseline & 79.3 & ${ }^{*} \mathrm{MCI}+$ normal & $\begin{array}{c}\text { No association } \\
\text { of IGF-I and } \\
\text { delirium }\end{array}$ \\
\hline Adamis et al. [98] & Medical & Longitudinal & 28 & $\begin{array}{c}\text { Baseline and } \\
\text { every } 3 \text { days } \\
(\max 4)\end{array}$ & $84.2,6.3$ & $\begin{array}{c}50 \% \text { with } \\
\text { dementia }+ \\
\text { MCI + normal }\end{array}$ & $\begin{array}{c}\text { Association of } \\
\text { IGF-I and all } \\
\text { delirium }\end{array}$ \\
\hline Morandi et al. [99] & ICU & Cohort & 40 & $\begin{array}{l}\text { Day before } \\
\text { assessment of } \\
\text { delirium }\end{array}$ & 65 (median) & No dementia & $\begin{array}{c}\text { No association } \\
\text { between IGF-I } \\
\text { and next-day } \\
\text { delirium }\end{array}$ \\
\hline
\end{tabular}

* MCI: Mild cognitive impairment.

Furthermore, from the same cohort, but with repeated measurements of IGF-I and other clinical and biological factors, they found that low levels of IGF-I were associated with any delirium (prevalent or incident) during the hospital stay and that low levels of IGF-I were associated with more severe delirium [98]. Lemstra et al. [97], in a case-control study, measured IGF-I levels preoperatively in elderly patients admitted for hip surgery and found no association between IGF-I levels and occurrence of postoperative delirium. Finally, Morandi et al. [99] found that previous-day IGF-I levels were not a risk factor for delirium occurrence the following day in mechanically ventilated medical Intensive Care Unit (ICU) patients. Overall, work to date has identified a possible link between altered IGF-I expression and delirium, but results have been contradictory.

\section{Possible Pathophysiological Mechanism(s)}

A range of possible mechanisms linking IGF-1 to delirium pathogenesis have been suggested and include the following.

6.1. Direct Protection of Neurons By IGF-I. Although no clear pathophysiological mechanism for delirium has been identified, increasing evidence suggests that delirium may be a neurotoxic state [21]. The neuroprotective actions of IGF-I may thus be relevant to delirium pathogenesis. IGF-I exerts neuroprotective actions in several types of neuronal cell types including cortical, hippocampal, and dopaminergic neurons. IGF-I protects neurons from cell death induced by various sorts of damage, including hypoglycemia, hyperglycemia, $\beta$-amyloid toxicity, osmotic stress, deprivation of specific growth and survival factors, low potassium and ceramide. However, the mechanisms of cell death after neuronal injury are speculative and depend upon the particular methods used to identify apoptotic cells [100]. Potential mechanisms thus include oxidative stress, excitotoxicity, apoptosis, autophagy, para-apoptosis, oncosis, and programmed or accidental necrosis $[101,102]$. IGF-I blocks apoptosis in damaged neurons via several mechanisms. In the acute phase after injury, IGF-I may delay apoptosis via activation of PI3K/Akt kinase and Ras/Raf/MEK/ERK pathways [103] and at a later second stage via pathways that are protein synthesis dependent (like bcl-xL) and linked to longer term survival $[101,104]$. Although the intracellular pathway of IGF-I receptor-dependent activation of the kinase Akt is a well defined mechanism, more recent studies support that, even in the absence of Akt and MEK dependent signaling, IGF-I can still prevent apoptosis but via another mechanism that requires p110a (a member of the phosphoinositide-3-kinase (PI3K) class) [105]. Similarly, it is proposed that neurons are directly protected by IGF-I and not via additional trophic support from glia [101], although more recent work indicates that glial cells are also major mediators of the protective actions of IGF-I [106]. In addition, it has been proposed that IGF-I is an important factor for promoting neural plasticity, neurogenesis, and memory such that altered IGF-I activity may have a direct impact upon the integrity of cellular processes that underpin cognition [107]. Improvement in behavioral and cognitive outcome was observed after administration of IGF-I in brain-injured animals [108]. Similarly, mutant mice with IGF-I deficiency show increased vulnerability to insult together with other brain deficits such as reduced neurogenesis and memory impairment, but these deficits can be reversed with administration of exogenous IGF-I [106]. In summary, low levels of IGF-I may increase the vulnerability of neurons and thus induce delirium, but, as IGF-I levels are increased during delirium by any mechanism(s), beneficial effects of IGF-I may assist in recovery from delirium. 
6.2. Dysregulation of the Somatotropic Axis. IGF-I has a pivotal role in the GRH/somatostatin-growth hormone IGFI axis, and its release is controlled by various feedback mechanisms. GH controls the secretion of IGF-I and is itself controlled by two hypothalamic peptides: grown hormone releasing hormone $(\mathrm{GHRH})$ which stimulates the synthesis and secretion of $\mathrm{GH}$, and Somatostatin (GHIH) which inhibits it. IGF-I expression in the liver is modulated by $\mathrm{GH}$, but this GH-stimulated IGF-I expression has also been observed in brain tissue. Increased IGF-I mRNA levels have been found in response to $\mathrm{GH}$ in dwarf mice, and, in hypophysectomized rats, the expression of IGF-I mRNA in the brain was four time less than in normal rats $[109,110]$. Levels of IGF-I expression recovered to near normal after injection of human $\mathrm{GH}$ into the hypophysectomized rats [110]. It seems that IGF-I is a major determinant of growth under GH modulation [111], and its expression in the brain is also GH dependent. There is also an age-related decrease in the secretion of $\mathrm{GH}$, which is principally the result of a reduction of the net stimulation of the pituitary gland by hypothalamic neurons rather than a lack of the secretory capacity of the pituitary gland [112]. In addition, frailty is associated with reduced levels of GH [113], and therapy with GH can increase energy, mood, concentration, memory, and general vitality. The effects of $\mathrm{GH}$ on cognition may reflect a direct effect of GH in the brain [112]. The role of IGF-I in delirium may reflect a wider disturbance of the somatotropic axis that can be clarified by studies that account for relative levels of IGF-I, GH, and its regulatory hormones.

6.3. Glucocorticoids. High levels of glucorticooids, dysregulation of HPA axis, and high levels of cortisol also have been linked to delirium occurrence $[32,114]$. IGF-I and glucocorticoid metabolism is also linked. Treatment of brain neuronal cultures with dexamethasone reduces IGF-I mRNA levels by $60 \%$ [115]. Similarly, dexamethasone decreases IGF-I mRNA levels in rat C6 glioma cells [116]. It has been suggested that this glucocorticoid-induced reduction in IGFI production occurs at the level of transcription. However, it is not clear if this reduced IGF-I expression by glucocorticoid is a result of a direct interaction between the activated glucocorticoid receptor and the IGF-I promoter [117].

6.4. Cytokine Effects. Delirium is strongly associated with infection and other inflammatory process [118]. Therapeutic use of cytokines (mainly interferons) can induce symptoms of delirium as an adverse effect [119]. It has been suggested that alterations of the aging immune response and the dysregulation of cytokines are the result of an age-related decrease of IGF-I and GH [89]. Animal studies indicate that IGF-I can activate the immune system [120], while studies in humans indicate that IGF-I levels can be regulated by IFN- $\gamma$ [121] and that IGF-I has significant interactions with a variety of cytokines including IL-6, TNF- $\alpha$, and IL$1 \beta[38,45-47]$. Thus, an emerging possibility is that direct interactions between cytokines and IGF-I may be relevant to their role in delirium. However, research to date has focused on a limited range of cytokines and their receptors or included a single measurement of IGF-I.

\section{Methodological Critique of the Studies}

7.1. Sample Sizes. All of the studies had small samples (from 12 to 40 delirious cases; see Table 1). As IGF-I levels are prone to considerable interindividual differences due to both genetic and environmental influences, these small sample sizes are especially prone to type II errors. Moreover, given that IGF-I has so many functions, interactions, homeostatic sensitivities that confounders abound and the small sample in some studies may have precluded the demonstration of other significant risk factors more important than IGF-I levels.

7.2. Selection Bias Based on Consent/Assent Issues. Delirium impacts considerably upon cognitive faculties that are relevant to capacity. In many cases, the principles described in the Declaration of Helsinki can allow for delirious patients to participate in research studies, but nevertheless the ethical challenges of the informed consent process, uncooperativeness in agitated or psychotic patients can impact upon ability to assent, and availability of proxy sources of consent [122] can impact upon recruitment [123]. Moreover, it is the nature of delirium to be fluctuating and transient, sometimes clearing in the time it takes to obtain assent from the patient's proxy [124]. Including only delirious subjects with capacity to consent can lead to selection bias with reduced generalisability of results. Such effects have been demonstrated in the Adamis et al. sample, where exclusion from analysis of incapacitated participants showed that the significant association of IGF-I and delirium were no longer evident [125]. Thus, the informed consent process can be an important factor which has been underestimated in delirium studies and is an important source of bias.

7.3. Longitudinal Design. The natural history of delirium is that of an often fluctuating condition. Similarly, IGFI concentrations fluctuate according to many factors (e.g., levels of other hormones, nutrition, cytokines). Free IGFI has an estimated half-life of 10-12 min, while the bound form (with IGFBP's) has an increased half-life in the range of 12-15 hours [126]. As such, longitudinal research designs are required in order to accurately capture the course and outcome of delirium and related factors, but the bulk of work to date has included assessments of IGF-I at a single time point rather than serial assessments.

7.4. Confounding Factors. Age is an important factor which influences IGF-I levels. Wilson et al. [96] studied an elderly population (75 years old and above), while that of Adamis et al. $[30,98]$ was 70 years and older. In contrast, Morandi et al. [99] studied a relatively younger population. However, all of the studies have controlled for age in their analyses and, as such, age span could not explain the different results. Albeit we need to be cautious with this interpretation as all of the studies involved small samples of average age more than 65. Similarly, severity of illness has been adjusted in all of the above studies, and, although the study of Morandi et al. [99] included more severely ill participants (as measured with the APACHE II score), existing evidence does not indicate that 
the severity of illness is a major factor explaining the disparity in study findings.

In addition, cognitive impairment can also impact upon findings and may contribute to discrepancies in reported studies. Morandi et al. [99] excluded participants with previous dementia. Lemstra et al. [97] and Wilson et al. [96] included participants with mild cognitive impairment, while, in the studies of Adamis et al. [30, 98], half of those studied had documented with DSM-IV dementia. Although, these differences in cognitive status may contribute to the differences in findings across studies, and low levels of IGF-I are associated with preexisting dementia rather than delirium, it can also be argued that if dementia is a risk factor of delirium and if IGF-I is associated with dementia and cognitive decline, we could expect that low levels of IGFI will be associated with delirium. It is relevant that studies that found an association adjusted for cognitive impairment indicate that both cognitive impairment and low IGF-I levels were independent risk factors for delirium.

The studies of IGF-I have not been matched by similar work investigating the role of related substances such as growth hormone (GH) and IGFBPs. GH has anabolic actions and increases plasma IGF-I in a dose-dependent way, but with a plateau effect [127]. A previous study [128] found that cerebrospinal fluid somatostatin (Growth hormone Inhibiting hormone) levels were significantly lower both during incident delirium and at 1 and 4 year followup. Although this finding does not directly link delirium with increased GH levels, it does point towards disturbance of the somatotropic axis during delirium. Indeed, in critically ill patients, low circulating IGF-I is associated with high GH levels [129]. However, exogenous administration of human growth hormone in frail elderly women after hip operation is associated with increased levels of both IGF-I and IGFBP-3 [113]. Thus, it is not clear how GH and IGF-I interact during delirium.

Similarly, IGF-I levels are also regulated by binding to multiple circulating proteins with IGFBP-3 accounting for $80-90 \%$ of IGF-I binding [58]. IGFBP-3 is a circulating IGF-I reservoir that may have neuroprotective and cell survival actions that are independent from those related to IGF-I [130]. IGFBP-1 is also an important regulator of IGF-I and has both inhibitory and enhancing effects on IGF-I. Moreover, IGFBP-1 levels are increased in old age and in those exposed to severe stress, nutritional deprivation, muscle wasting, and inflammation [131]. In addition, insulin is another important factor that has not been examined to date. Insulin enhances the production of IGF-I and increases IGF-I levels in conditions where GH levels are decreased [34].

Accounting for all of the factors that can influence IGF-I levels is challenging, but studies to date still have not investigated many important basic factors such as GH and IGFBPs.

7.5. Outcome. Most of the reported studies examined IGF-I levels as a risk factor for delirium. One study investigated the levels of IGF-I together with other factors (cytokines and APOE genotype) as predictors for recovery [30]. Interestingly those delirious patients with lower initial levels of
IGF-I were also those who finally recovered from delirium. Although the results of this study need to be interpreted with caution because of the small sample size, it seems that a feedback mechanism maintains IGF-I levels above a minimum, and, in those with delirium who ultimately recover IGF-I levels steadily increase over time.

Ultimately, in addition to the possibility than IGF-I may be a causal factor in delirium, its neuroprotective effects point to a possible role in facilitating recovery from delirium.

\section{Conclusions and Recommendations}

The widespread role of IGF-I in regulating bodily metabolic and brain functioning, as well as its capacity to connect these systems to allow for adaptive response to changing environmental demands, makes it an attractive candidate for study of a potential role in the pathophysiology of deliriuma condition that reflects widespread brain dysfunction in response to a variety of peripheral metabolic stressors. Studies to date indicate that IGF-I can have an important role in the cellular processes that underpin ageing and cognition, but specific studies of IGF-I in delirium have produced somewhat conflicting results. The nature of this relationship may be complex in that IGF-I levels may be relevant to delirium proneness, the occurrence of delirium episodes, and/or factors relevant to delirium recovery. A direct causal relationship of disturbed IGF-I expression with delirium could be identified by cross-sectional studies, although confounding factors such as age, frailty, baseline cognitive status, as well as selection bias need to be considered in interpreting results. More complex relationships require longitudinal studies in order to clarify the relevance of IGF-I to delirium status over time. More pragmatic observational studies are required that include greater numbers of representative patients and that investigate multiple biological factors to clarify the extent to which the role of IGF-I as a predictive factor for delirium is an independent or surrogate factor. Greater understanding of the role of IGF-I and related factors in delirium pathogenesis can inform efforts to design clinical trials involving administration of exogenous IGF-I.

\section{References}

[1] American Psychiatric Association, Task Force on DSMIV, DSM-IV: Diagnostic and Statistical Manual of Mental Disorders, American Psychiatric Association, Washington, DC, USA, 4th edition, 1994.

[2] N. Siddiqi, A. O. House, and J. D. Holmes, "Occurrence and outcome of delirium in medical in-patients: a systematic literature review," Age and Ageing, vol. 35, no. 4, pp. 350-364, 2006.

[3] M. Elie, F. Rousseau, M. Cole, F. Primeau, J. McCusker, and F. Bellavance, "Prevalence and detection of delirium in elderly emergency department patients," Canadian Medical Association Journal, vol. 163, no. 8, pp. 977-981, 2000.

[4] L. J. Young and J. George, "Do guidelines improve the process and outcomes of care in delirium?" Age and Ageing, vol. 32, no. 5 , pp. 525-528, 2003. 
[5] D. Meagher, "More attention, less confusion: time to lessen the burden of delirium," International Review of Psychiatry, vol. 21, no. 1, pp. 1-3, 2009.

[6] P. Trzepacz, D. Meagher, and M. Leonard, "Delirium," in Textbook of Psychosomatic Medicine, J. Levenson, Ed., American Psychiatric Press, Washington, DC, USA, 2010.

[7] Y. Gustafson, D. Berggren, B. Brannstrom et al., "Acute confusional states in elderly patients treated for femoral neck fracture," Journal of the American Geriatrics Society, vol. 36, no. 6, pp. 525-530, 1988.

[8] K. Rockwood, "Acute confusion in elderly medical patients," Journal of the American Geriatrics Society, vol. 37, no. 2, pp. 150-154, 1989.

[9] S. E. Levkoff, D. A. Evans, B. Liptzin et al., "Delirium: the occurrence and persistence of symptoms among elderly hospitalized patients," Archives of Internal Medicine, vol. 152, no. 2, pp. 334-340, 1992.

[10] J. D. Schor, S. E. Levkoff, L. A. Lipsitz et al., "Risk factors for delirium in hospitalized elderly," Journal of the American Medical Association, vol. 267, no. 6, pp. 827-831, 1992.

[11] M. Elie, M. G. Cole, F. J. Primeau, and F. Bellavance, "Delirium risk factors in elderly hospitalized patients," Journal of General Internal Medicine, vol. 13, no. 3, pp. 204-212, 1998.

[12] A. Hofman, W. A. Rocca, C. Brayne et al., "The prevalence of dementia in Europe: a collaborative study of 1980-1990 findings," International Journal of Epidemiology, vol. 20, no. 3, pp. 736-748, 1991.

[13] D. M. Fick, J. V. Agostini, and S. K. Inouye, "Delirium superimposed on dementia: a systematic review," Journal of the American Geriatrics Society, vol. 50, no. 10, pp. 17231732, 2002.

[14] L. Ansaloni, F. Catena, R. Chattat et al., "Risk factors and incidence of postoperative delirium in elderly patients after elective and emergency surgery," British Journal of Surgery, vol. 97, no. 2, pp. 273-280, 2010.

[15] A. Chrispal, K. Prasad Mathews, and V. Surekha, "The clinical profile and association of delirium in geriatric patients with hip fractures in a tertiary care hospital in India," Journal of Association of Physicians of India, vol. 58, no. 1, pp. 15-19, 2010.

[16] J. G. Franco, C. Valencia, C. Bernal et al., "Relationship between cognitive status at admission and incident delirium in older medical inpatients," Journal of Neuropsychiatry and Clinical Neurosciences, vol. 22, no. 3, pp. 329-337, 2010.

[17] D. B. Rolfson, J. E. McElhaney, G. S. Jhangri, and K. Rockwood, "Delirium: validity of the confusion assessment method in detecting postoperative delirium in the elderly," International Psychogeriatrics, vol. 11, no. 4, pp. 431-438, 1999.

[18] M. W. A. van Rijsbergen, A. W. Oldenbeuving, R. E. Nieuwenhuis-Mark et al., "Delirium in acute stroke: a predictor 7 of subsequent cognitive impairment? A two-year followup study," Journal of the Neurological Sciences, vol. 306, no. 1-2, pp. 138-142, 2011.

[19] K. Alagiakrishnan and C. A. Wiens, "An approach to drug induced delirium in the elderly," Postgraduate Medical Journal, vol. 80, no. 945, pp. 388-393, 2004.

[20] A. Clegg and J. B. Young, "Which medications to avoid in people at risk of delirium: a systematic review," Age and Ageing, vol. 40, no. 1, pp. 23-29, 2011.

[21] A. M. J. MacLullich, A. Beaglehole, R. J. Hall, and D. J. Meagher, "Delirium and long-term cognitive impairment," International Review of Psychiatry, vol. 21, no. 1, pp. 30-42, 2009.
[22] K. Rockwood, "The occurrence and duration of symptoms in elderly patients with delirium," Journals of Gerontology, vol. 48, no. 4, pp. M162-M166, 1993.

[23] J. McCusker, M. Cole, N. Dendukuri, L. Han, and E. Belzile, "The course of delirium in older medical inpatients: a prospective study," Journal of General Internal Medicine, vol. 18, no. 9, pp. 696-704, 2003.

[24] D. Adamis, A. Treloar, F. C. Martin, and A. J. D. Macdonald, "Recovery and outcome of delirium in elderly medical inpatients," Archives of Gerontology and Geriatrics, vol. 43, no. 2, pp. 289-298, 2006.

[25] J. C. Jackson, S. M. Gordon, R. P. Hart, R. O. Hopkins, and E. W. Ely, "The association between delirium and cognitive decline: a review of the empirical literature," Neuropsychology Review, vol. 14, no. 2, pp. 87-98, 2004.

[26] M. A. Rudberg, P. Pompei, M. D. Foreman, R. E. Ross, and C. K. Cassel, "The natural history of delirium in older hospitalized patients: a syndrome of heterogeneity," Age and Ageing, vol. 26, no. 3, pp. 169-174, 1997.

[27] A. J. D. Macdonald and A. Treloar, "Delirium and dementia; are they distinct?" Journal of the American Geriatrics Society, vol. 44 , no. 8, pp. 1001-1002, 1996.

[28] T. G. Fong, R. N. Jones, P. Shi et al., "Delirium accelerates cognitive decline in alzheimer disease," Neurology, vol. 72, no. 18, pp. 1570-1575, 2009.

[29] D. J. Meagher, A. M. J. MacLullich, and J. V. Laurila, "Defining delirium for the International Classification of Diseases, 11th Revision," Journal of Psychosomatic Research, vol. 65, no. 3, pp. 207-214, 2008.

[30] D. Adamis, A. Treloar, F. C. Martin, N. Gregson, G. Hamilton, and A. J. D. Macdonald, "APOE and cytokines as biological markers for recovery of prevalent delirium in elderly medical inpatients," International Journal of Geriatric Psychiatry, vol. 22, no. 7, pp. 688-694, 2007.

[31] S. E. de Rooij, B. C. van Munster, J. C. Korevaar, and M. Levi, "Cytokines and acute phase response in delirium," Journal of Psychosomatic Research, vol. 62, no. 5, pp. 521-525, 2007.

[32] A. M. J. MacLullich, K. J. Ferguson, T. Miller, S. E. J. A. de Rooij, and C. Cunningham, "Unravelling the pathophysiology of delirium: a focus on the role of aberrant stress responses," Journal of Psychosomatic Research, vol. 65, no. 3, pp. 229-238, 2008.

[33] C. Alexia, G. Fallot, M. Lasfer, G. Schweizer-Groyer, and A. Groyer, "An evaluation of the role of insulin-like growth factors (IGF) and of type-I IGF receptor signalling in hepatocarcinogenesis and in the resistance of hepatocarcinoma cells against drug-induced apoptosis," Biochemical Pharmacology, vol. 68, no. 6, pp. 1003-1015, 2004.

[34] B. R. Lackey, S. L. Gray, and D. M. Henricks, "Actions and interactions of the IGF system in Alzheimer's disease: review and hypotheses," Growth Hormone and IGF Research, vol. 10, no. 1, pp. 1-13, 2000.

[35] I. Torres-Aleman, "Toward a comprehensive neurobiology of IGF-I," Developmental Neurobiology, vol. 70, no. 5, pp. 384396, 2010.

[36] C. P. Velloso, "Regulation of muscle mass by growth hormone and IGF-I," British Journal of Pharmacology, vol. 154, no. 3, pp. 557-568, 2008.

[37] F. M. Yang, S. K. Inouye, M. A. Fearing, D. K. Kiely, E. R. Marcantonio, and R. N. Jones, "Participation in activity and risk for incident delirium," Journal of the American Geriatrics Society, vol. 56, no. 8, pp. 1479-1484, 2008.

[38] H. D. Venters, S. R. Broussard, J. H. Zhou et al., "Tumor necrosis factor $\alpha$ and insulin-like growth factor-I in the brain: 
is the whole greater than the sum of its parts?" Journal of Neuroimmunology, vol. 119, no. 2, pp. 151-165, 2001.

[39] J. A. D'Ercole, P. Ye, and J. R. O’Kusky, “Mutant mouse models of insulin-like growth factor actions in the central nervous system," Neuropeptides, vol. 36, no. 2-3, pp. 209-220, 2002.

[40] S. T. O'Keeffe and J. N. Lavan, "Predicting delirium in elderly patients: development and validation of a risk-stratification model," Age and Ageing, vol. 25, no. 4, pp. 317-321, 1996.

[41] S. K. Inouye and P. A. Charpentier, "Precipitating factors for delirium in hospitalized elderly persons: predictive model and interrelationship with baseline vulnerability," Journal of the American Medical Association, vol. 275, no. 11, pp. 852$857,1996$.

[42] S. Doré, S. Kar, and R. Quirion, "Insulin-like growth factor I protects and rescues hippocampal neurons against $\beta$ amyloid- and human amylin-induced toxicity," Proceedings of the National Academy of Sciences of the United States of America, vol. 94, no. 9, pp. 4772-4777, 1997.

[43] P. J. Jenkens and S. A. Bustin, "Evidence for a link between IGF-I and cancer," European Journal of Endocrinology, vol. 151, supplement 1, pp. S17-S22, 2004.

[44] A. Meager, The Molecular Biology of Cytokines, John Wiley \& Sons, Chichester, UK, 1998.

[45] F. De Benedetti, T. Alonzi, A. Moretta et al., "Interleukin 6 causes growth impairment in transgenic mice through a decrease in insulin-like growth factor-I: a model for stunted growth in children with chronic inflammation," Journal of Clinical Investigation, vol. 99, no. 4, pp. 643-650, 1997.

[46] B. R. Lackey, S. L. Gray, and D. M. Henricks, "Does the insulin-like growth factor system interact with prostaglandins and proinflammatory cytokines during neurodegeneration?" Experimental Biology and Medicine, vol. 224, no. 1, pp. 20-27, 2000.

[47] C. H. Lang, L. Hong-Brown, and R. A. Frost, "Cytokine inhibition of JAK-STAT signaling: a new mechanism of growth hormone resistance," Pediatric Nephrology, vol. 20, no. 3, pp. 306-312, 2005.

[48] L. J. Niedernhofer, G. A. Garinis, A. Raams et al., "A new progeroid syndrome reveals that genotoxic stress suppresses the somatotroph axis," Nature, vol. 444, no. 7122, pp. 10381043, 2006.

[49] Y. Li, W. Xu, M. W. McBurney, and V. D. Longo, "SirT1 inhibition reduces IGF-I/IRS-2/Ras/ERK1/2 signaling and protects neurons," Cell Metabolism, vol. 8, no. 1, pp. 38-48, 2008.

[50] D. Rudman, M. H. Kutner, and C. M. Rogers, "Impaired growth hormone secretion in the adult population: relation to age and adiposity," Journal of Clinical Investigation, vol. 67, no. 5, pp. 1361-1369, 1981.

[51] D. R. Clemmons and J. J. Van Wyk, "Factors controlling blood concentration of somatomedin C," Clinics in Endocrinology and Metabolism, vol. 13, no. 1, pp. 113-143, 1984.

[52] K. Landin-Wilhelmsen, L. Wilhelmsen, G. Lappas et al., "Serum insulin-like growth factor I in a random population sample of men and women: relation to age, sex, smoking habits, coffee consumption and physical activity, blood pressure and concentrations of plasma lipids, fibrinogen, parathyroid hormone and osteocalcin," Clinical Endocrinology, vol. 41, no. 3, pp. 351-357, 1994.

[53] S. Boonen, E. Lesaffre, J. Dequeker et al., "Relationship between baseline insulin-like growth factor-I (IGF-I) and femoral bone density in women aged over 70 years: potential implications for the prevention of age-related bone loss,"
Journal of the American Geriatrics Society, vol. 44, no. 11, pp. 1301-1306, 1996.

[54] J. A. M. J. L. Janssen, R. P. Stolk, H. A. P. Pols, D. E. Grobbee, F. H. De Jong, and S. W. J. Lamberts, "Serum free IGF-I, total IGF-I, IGFBP-1 and IGFBP-3 levels in an elderly population: relation to age and sex steroid levels," Clinical Endocrinology, vol. 48, no. 4, pp. 471-478, 1998.

[55] A. Juul, K. Main, W. F. Blum, J. Lindholm, M. B. Ranke, and N. E. Skakkebaek, "The ratio between serum levels of insulinlike growth factor (IGF)-I and the IGF binding proteins (IGFBP-1, 2 and 3) decreases with age in healthy adults and is increased in acromegalic patients," Clinical Endocrinology, vol. 41, no. 1, pp. 85-93, 1994.

[56] G. Paolisso, S. Ammendola, A. Del Buono et al., "Serum levels of insulin-like growth factor-I (IGF-I) and IGF-binding protein-3 in healthy centenarians: relationship with plasma leptin and lipid concentrations, insulin action, and cognitive function," Journal of Clinical Endocrinology and Metabolism, vol. 82, no. 7, pp. 2204-2209, 1997.

[57] Y. Arai, N. Hirose, K. Yamamura et al., "Serum insulin-like growth factor-1 in centenarians: implications of IGF-1 as a rapid turnover protein," Journals of Gerontology A, vol. 56, no. 2, pp. M79-M82, 2001.

[58] F. C. Martin, "Growth hormone, aging and frailty," Reviews in Clinical Gerontology, vol. 9, no. 3, pp. 207-214, 1999.

[59] J. L. Thompson, G. E. Butterfield, R. Marcus et al., "The effects of recombinant human insulin-like growth factorI and growth hormone on body composition in elderly women," Journal of Clinical Endocrinology and Metabolism, vol. 80, no. 6, pp. 1845-1852, 1995.

[60] K. C. Copeland, R. B. Colletti, J. T. Devlin, and T. L. McAuliffe, "The relationship between insulin-like growth factor-I, adiposity, and aging," Metabolism, vol. 39, no. 6, pp. 584-587, 1990.

[61] T. B. Harris, D. Kiel, R. Roubenoff et al., "Association of insulin-like growth factor-I with body composition, weight history, and past health behaviors in the very old: the Framingham Heart Study," Journal of the American Geriatrics Society, vol. 45, no. 2, pp. 133-139, 1997.

[62] A. R. Cappola, K. Bandeen-Roche, G. S. Wand, S. Volpato, and L. P. Fried, "Association of IGF-I levels with muscle strength and mobility in older women," Journal of Clinical Endocrinology and Metabolism, vol. 86, no. 9, pp. 4139-4146, 2001.

[63] A. R. Cappola, Q. L. Xue, L. Ferrucci, J. M. Guralnik, S. Volpato, and L. P. Fried, "Insulin-like growth factor I and interleukin-6 contribute synergistically to disability and mortality in older women," Journal of Clinical Endocrinology and Metabolism, vol. 88, no. 5, pp. 2019-2025, 2003.

[64] R. Roubenoff, H. Parise, H. A. Payette et al., "Cytokines, insulin-like growth factor 1, sarcopenia, and mortality in very old community-dwelling men and women: the Framingham Heart Study," American Journal of Medicine, vol. 115, no. 6, pp. 429-435, 2003.

[65] M. Andreassen, I. Raymond, C. Kistorp, P. Hildebrandt, J. Eaber, and L. $\varnothing$. Kristensen, "IGF1 as predictor of all cause mortality and cardiovascular disease in an elderly population," European Journal of Endocrinology, vol. 160, no. 1, pp. 25-31, 2009.

[66] G. A. Laughlin, E. Barrett-Connor, M. H. Criqui, and D. Kritz-Silverstein, "The prospective association of serum insulin-like growth factor I (IGF-I) and IGF-binding protein1 levels with all cause and cardiovascular disease mortality in older adults: the Rancho Bernardo study," Journal of Clinical 
Endocrinology and Metabolism, vol. 89, no. 1, pp. 114-120, 2004.

[67] S. Saydah, B. Graubard, R. Ballard-Barbash, and D. Berrigan, "Insulin-like growth factors and subsequent risk of mortality in the United States," American Journal of Epidemiology, vol. 166, no. 5, pp. 518-526, 2007.

[68] K. A. Woods, C. Camacho-Hübner, M. O. Savage, and A. J. L. Clark, "Intrauterine growth retardation and postnatal growth failure associated with deletion of the insulin-like growth factor I gene," New England Journal of Medicine, vol. 335, no. 18, pp. 1363-1367, 1996.

[69] C. M. Cheng, R. R. Reinhardt, W. H. Lee, G. Joncas, S. C. Patel, and C. A. Bondy, "Insulin-like growth factor 1 regulates developing brain glucose metabolism," Proceedings of the National Academy of Sciences of the United States of America, vol. 97, no. 18, pp. 10236-10241, 2000.

[70] K. D. Beck, L. Powell-Braxton, H. R. Widmer, J. Valverde, and F. Hefti, "Igf1 gene disruption results in reduced brain size, CNS hypomyelination, and loss of hippocampal granule and striatal parvalbumin-containing neurons," Neuron, vol. 14, no. 4, pp. 717-730, 1995.

[71] J. B. Deijen, H. De Boer, and E. A. Van Der Veen, "Cognitive changes during growth hormone replacement in adult men," Psychoneuroendocrinology, vol. 23, no. 1, pp. 45-55, 1998.

[72] M. A. Papadakis, D. Grady, D. Black et al., "Growth hormone replacement in healthy older men improves body composition but not functional ability," Annals of Internal Medicine, vol. 124, no. 8, pp. 708-716, 1996.

[73] A. Aleman, W. R. De Vries, E. H. F. De Haan, H. J. J. Verhaar, M. M. Samson, and H. P. F. Koppeschaar, "Agesensitive cognitive function, growth hormone and insulinlike growth factor 1 plasma levels in healthy older men," Neuropsychobiology, vol. 41, no. 2, pp. 73-78, 2000.

[74] A. Aleman, H. J. J. Verhaar, E. H. F. De Haan et al., "Insulinlike growth factor-I and cognitive function in healthy older men," Journal of Clinical Endocrinology and Metabolism, vol. 84, no. 2, pp. 471-475, 1999.

[75] A. Mustafa, L. Lannfelt, L. Lilius, A. Islam, B. Winblad, and A. Adem, "Decreased plasma insulin-like growth factor-I level in familial Alzheimer's disease patients carrying the Swedish APP 670/671 mutation," Dementia and Geriatric Cognitive Disorders, vol. 10, no. 6, pp. 446-451, 1999.

[76] G. Murialdo, A. Barreca, F. Nobili et al., "Relationships between cortisol, dehydroepiandrosterone sulphate and insulin-like growth factor-I system in dementia," Journal of Endocrinological Investigation, vol. 24, no. 3, pp. 139-146, 2001.

[77] V. R. Sara, K. Hall, and K. Enzell, "Somatomedins in aging and dementia disorders of the Alzheimer type," Neurobiology of Aging, vol. 3, no. 2, pp. 117-120, 1982.

[78] A. Tham, A. Nordberg, F. E. Grissom, C. Carlsson-Skwirut, M. Viitanen, and V. R. Sara, "Insulin-like growth factors and insulin-like growth factor binding proteins in cerebrospinal fluid and serum of patients with dementia of the Alzheimer type," Journal of Neural Transmission Parkinson's Disease and Dementia Section, vol. 5, no. 3, pp. 165-176, 1993.

[79] B. Nasmanl, T. Olsson, J. R. Seckl et al., "Abnormalities in adrenal androgens, but not of glucocorticoids, in early Alzheimer's disease," Psychoneuroendocrinology, vol. 20, no. 1, pp. 83-94, 1995.

[80] E. Carro, J. L. Trejo, T. Gomez-Isla, D. LeRoith, and I. TorresAleman, "Serum insulin-like growth factor I regulates brain amyloid- $\beta$ levels," Nature Medicine, vol. 8, no. 12, pp. 1390 1397, 2002.
[81] W. Q. Zhao, P. N. Lacor, H. Chen et al., "Insulin receptor dysfunction impairs cellular clearance of neurotoxic oligomeric A $\beta$," Journal of Biological Chemistry, vol. 284, no. 28, pp. 18742-18753, 2009.

[82] S. Sharma, J. Prasanthi, E. Schommer, G. Feist, and O. Ghribi, "Hypercholesterolemia-induced $\mathrm{A} \beta$ accumulation in rabbit brain is associated with alteration in IGF-1 signaling," Neurobiology of Disease, vol. 32, no. 3, pp. 426-432, 2008.

[83] S. Kar, D. Seto, S. Doré, U. K. Hanisch, and R. Quirion, "Insulin-like growth factors-I and -II differentially regulate endogenous acetylcholine release from the rat hippocampal formation," Proceedings of the National Academy of Sciences of the United States of America, vol. 94, no. 25, pp. 14054-14059, 1997.

[84] M. A. I. Åberg, N. D. Åberg, H. Hedbäcker, J. Oscarsson, and P. S. Eriksson, "Peripheral infusion of IGF-I selectively induces neurogenesis in the adult rat hippocampus," Journal of Neuroscience, vol. 20, no. 8, pp. 2896-2903, 2000.

[85] M. A. I. Åberg, N. D. Åberg, T. D. Palmer et al., "IGF-I has a direct proliferative effect in adult hippocampal progenitor cells," Molecular and Cellular Neuroscience, vol. 24, no. 1, pp. 23-40, 2003.

[86] S. Doré, S. Bastianetto, S. Kar, and R. Quirion, "Protective and rescuing abilities of IGF-I and some putative free radical scavengers against $\beta$-amyloid-inducing toxicity in neurons," Annals of the New York Academy of Sciences, vol. 890, pp. 356364, 1999.

[87] L. Gasparini and H. Xu, "Potential roles of insulin and IGF-1 in Alzheimer's disease," Trends in Neurosciences, vol. 26, no. 8, pp. 404-406, 2003.

[88] E. Giovannucci, "Nutrition, insulin, insulin-like growth factors and cancer," Hormone and Metabolic Research, vol. 35, no. 11-12, pp. 694-704, 2003.

[89] W. M. Zawada, D. L. Kirschman, J. J. Cohen, K. A. Heidenreich, and C. R. Freed, "Growth factors rescue embryonic dopamine neurons from programmed cell death," Experimental Neurology, vol. 140, no. 1, pp. 60-67, 1996.

[90] W. M. Zawada, D. J. Zastrow, E. D. Clarkson, F. S. Adams, K. P. Bell, and C. R. Freed, "Growth factors improve immediate survival of embryonic dopamine neurons after transplantation into rats," Brain Research, vol. 786, no. 1-2, pp. 96-103, 1998.

[91] J. Guan, R. Krishnamurthi, H. J. Waldvogel, R. L. M. Faull, R. Clark, and P. Gluckman, "N-terminal tripeptide of IGF1 (GPE) prevents the loss of TH positive neurons after 6OHDA induced nigral lesion in rats," Brain Research, vol. 859, no. 2, pp. 286-292, 2000.

[92] R. Krishnamurthi, S. Stott, M. Maingay et al., "N-terminal tripeptide of IGF-I improves functional deficits after 6OHDA lesion in rats," NeuroReport, vol. 15, no. 10, pp. 16011604, 2004.

[93] P. T. Trzepacz, "The neuropathogenesis of delirium: a need to focus our research," Psychosomatics, vol. 35, no. 4, pp. 374391, 1994.

[94] P. T. Trzepacz, "Update on the neuropathogenesis of delirium," Dementia and Geriatric Cognitive Disorders, vol. 10, no. 5, pp. 330-334, 1999.

[95] C. Murray, D. J. Sanderson, C. Barkus et al., "Systemic inflammation induces acute working memory deficits in the primed brain: relevance for delirium," Neurobiology of Aging. In press.

[96] K. Wilson, C. Broadhurst, M. Diver, M. Jackson, and P. Mottram, "Plasma insulin growth factor-1 and incident 
delirium in older people," International Journal of Geriatric Psychiatry, vol. 20, no. 2, pp. 154-159, 2005.

[97] A. W. Lemstra, K. J. Kalisvaart, R. Vreeswijk, W. A. van Gool, and P. Eikelenboom, "Pre-operative inflammatory markers and the risk of postoperative delirium in elderly patients," International Journal of Geriatric Psychiatry, vol. 23, no. 9, pp. 943-948, 2008.

[98] D. Adamis, M. Lunn, F. C. Martin et al., "Cytokines and IGF-I in delirious and non-delirious acutely ill older medical inpatients," Age and Ageing, vol. 38, no. 3, pp. 326-332, 2009.

[99] A. Morandi, M. L. Gunther, P. P. Pandharipande et al., "Insulin-like growth factor-1 and delirium in critically ill mechanically ventilated patients: a preliminary investigation," International Psychogeriatrics. In press.

[100] C. Charriaut-Marlangue and Y. Ben-Ari, "A cautionary note on the use of the TUNEL stain to determine apoptosis," NeuroReport, vol. 7, no. 1, pp. 61-64, 1995.

[101] P. D. Gluckman, J. Guan, C. Williams et al., "Asphyxial brain injury-the role of the IGF system," Molecular and Cellular Endocrinology, vol. 140, no. 1-2, pp. 95-99, 1998.

[102] C. D. M. Filho and M. Holzenberger, "IGF receptors in the adult brain," in IGFs: Local Repair and Survival Factors Throughout Life Span, D. Clemmons, I. C. A. F. Robinson, and Y. Christen, Eds., pp. 125-142, Springer, London, UK, 2010.

[103] F. Peruzzi, M. Prisco, M. Dews et al., "Multiple signaling pathways of the insulin-like growth factor 1 receptor in protection from apoptosis," Molecular and Cellular Biology, vol. 19, no. 10, pp. 7203-7215, 1999.

[104] M. Párrizas and D. LeRoith, "Insulin-like growth factor-1 inhibition of apoptosis is associated with increased expression of the bcl-xL gene product," Endocrinology, vol. 138, no. 3, pp. 1355-1358, 1997.

[105] R. W. Matheny and M. L. Adamo, "PI3K p110 alpha and p110 beta have differential effects on Akt activation and protection against oxidative stress-induced apoptosis in myoblasts," Cell Death and Differentiation, vol. 17, no. 4, pp. 677-688, 2010.

[106] E. Carro, J. L. Trejo, S. Fernandez, A. M. Fernandez, and I. Torres-Aleman, "Insulin-like growth factor-I and neuroprotection," in The Somatotrophic Axis in Brain Function, F. Nyberg, Ed., Elsevier Academic Press, London, UK, 2006.

[107] R. Yirmiya and I. Goshen, "Immune modulation of learning, memory, neural plasticity and neurogenesis," Brain, Behavior, and Immunity, vol. 25, no. 2, pp. 181-213, 2011.

[108] K. E. Saatman, P. C. Contreras, D. H. Smith et al., "Insulinlike growth factor-1 (IGF-1) improves both neurological motor and cognitive outcome following experimental brain injury," Experimental Neurology, vol. 147, no. 2, pp. 418-427, 1997.

[109] L. S. Mathews, G. Norstedt, and R. D. Palmiter, "Regulation of insulin-like growth factor I gene expression by growth hormone," Proceedings of the National Academy of Sciences of the United States of America, vol. 83, no. 24, pp. 9343-9347, 1986.

[110] M. A. Hynes, J. J. Van Wijk, P. J. Brooks, A. J. D’Ercole, M. Jansen, and P. K. Lund, "Growth hormone dependence of somatomedin-C/insulin-like growth factor-I and insulinlike growth factor-II messenger ribonucleic acids," Molecular Endocrinology, vol. 1, no. 3, pp. 233-242, 1987.

[111] F. Lupu, J. D. Terwilliger, K. Lee, G. V. Segre, and A. Efstratiadis, "Roles of growth hormone and insulin-like growth factor 1 in mouse postnatal growth," Developmental Biology, vol. 229, no. 1, pp. 141-162, 2001.
[112] O. Khorram, "Use of growth hormone and growth hormone secretagogues in aging: help or harm," Clinical Obstetrics and Gynecology, vol. 44, no. 4, pp. 893-901, 2001.

[113] A. L. Yeo, D. Levy, F. C. Martin et al., "Frailty and the biochemical effects of recombinant human growth hormone in women after surgery for hip fracture," Growth Hormone and IGF Research, vol. 13, no. 6, pp. 361-370, 2003.

[114] A. Pearson, A. De Vries, S. D. Middleton et al., "Cerebrospinal fluid cortisol levels are higher in patients with delirium versus controls," BMC Research Notes, vol. 3, Article ID 33, 2010.

[115] M. Adamo, H. Werner, W. Farnsworth, C. T. Roberts, M. Raizada, and D. LeRoith, "Dexamethasone reduces steady state insulin-like growth factor I messenger ribonucleic acid levels in rat neuronal and glial cells in primary culture," Endocrinology, vol. 123, no. 5, pp. 2565-2570, 1988.

[116] W. L. Lowe Jr., T. Meyer, C. W. Karpen, and L. R. Lorentzen, "Regulation of insulin-like growth factor I production in rat C6 glioma cells: possible role as an autocrine/paracrine growth factor," Endocrinology, vol. 130, no. 5, pp. 2683-2691, 1992.

[117] C. B. Chan, M. C. Tse, and C. H. K. Cheng, "Regulation and mechanism of growth hormone and insulin-like growth factor-I biosynthesis and secretion," in The Somatotrophic Axis in Brain Function, F. Nyberg, Ed., pp. 7-23, Elsevier Academic Press, London, UK, 2006.

[118] C. Broadhurst and K. Wilson, "Immunology of delirium: new opportunities for treatment and research," British Journal of Psychiatry, vol. 179, pp. 288-289, 2001.

[119] O. Nozaki, C. Takagi, K. Takaoka, T. Takata, and M. Yoshida, "Psychiatric manifestations accompanying interferon therapy for patients with chronic hepatitis C: an overview of cases in Japan," Psychiatry and Clinical Neurosciences, vol. 51, no. 4, pp. 175-180, 1997.

[120] C. J. Auernhammer and C. J. Strasburger, "Effects of growth hormone and insulin-like growth factor I on the immune system," European Journal of Endocrinology, vol. 133, no. 6, pp. 635-645, 1995.

[121] V. Hwa, B. Little, E. M. Kofoed, and R. G. Rosenfeld, "Transcriptional regulation of insulin-like growth factor-I by interferon-gamma requires STAT-5b," Journal of Biological Chemistry, vol. 279, no. 4, pp. 2728-2736, 2004.

[122] D. Adamis, F. C. Martin, A. Treloar, and A. J. D. Macdonald, "Capacity, consent, and selection bias in a study of delirium," Journal of Medical Ethics, vol. 31, no. 3, pp. 137-143, 2005.

[123] K. B. Auerswald, P. A. Charpentier, and S. K. Inouye, "The informed consent process in older patients who developed delirium: a clinical epidemiologic study," American Journal of Medicine, vol. 103, no. 5, pp. 410-418, 1997.

[124] J. Francis, "A half-century of delirium research: time to close the gap," Journal of the American Geriatrics Society, vol. 43, no. 5, pp. 585-586, 1995.

[125] D. Adamis, A. Treloar, F. C. Martin, and A. J. D. Macdonald, "Ethical research in delirium: arguments for including decisionally incapacitated subjects," Science and Engineering Ethics, vol. 16, no. 1, pp. 169-174, 2010.

[126] H. P. Guler, J. Zapf, C. Schmid, and E. R. Froesch, "Insulinlike growth factors I and II in healthy man. Estimations of half-lives and production rates," Acta Endocrinologica, vol. 121, no. 6, pp. 753-758, 1989.

[127] A. L. Barkan, "Defining normalcy of the somatotropic axis: an attainable goal?" Pituitary, vol. 10, no. 2, pp. 135-139, 2007. 
[128] H. J. Koponen, E. Leinonen, U. Lepola, and P. J. Riekkinen, "A long-term follow-up study of cerebrospinal fluid somatostatin in delirium," Acta Psychiatrica Scandinavica, vol. 89, no. 5, pp. 329-334, 1994.

[129] R. Ross, J. Miell, E. Freeman et al., "Critically ill patients have high basal growth hormone levels with attenuated oscillatory activity associated with low levels of insulin-like growth factor-I," Clinical Endocrinology, vol. 35, no. 1, pp. 47-54, 1991.

[130] P. Cohen, "Insulin-like growth factor binding protein-3: insulin-like growth factor independence comes of age," Endocrinology, vol. 147, no. 5, pp. 2109-2111, 2006.

[131] R. C. Kaplan, A. P. McGinn, M. N. Pollak et al., "Total insulinlike growth factor 1 and insulinlike growth factor binding protein levels, functional status, and mortality in older adults," Journal of the American Geriatrics Society, vol. 56, no. 4, pp. 652-660, 2008. 


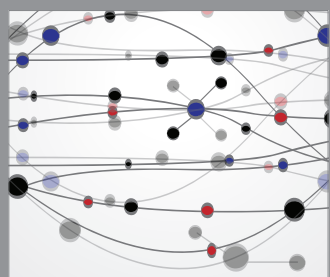

The Scientific World Journal
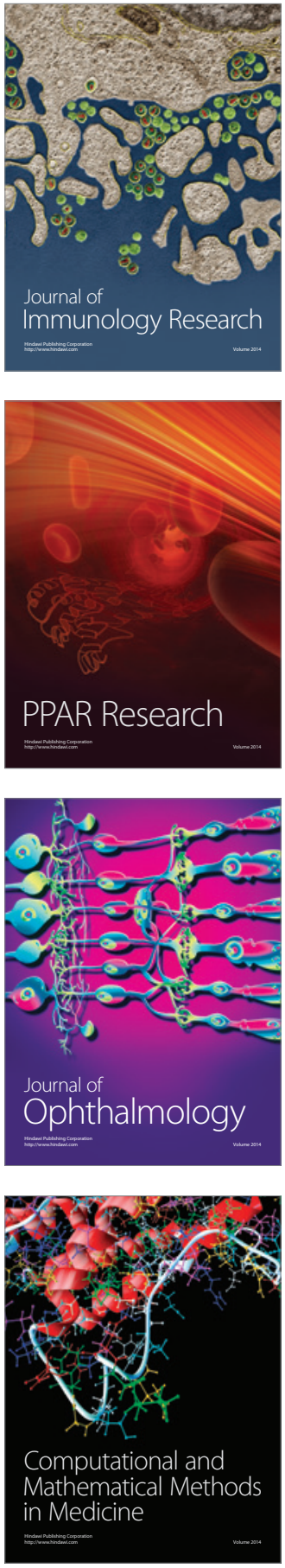

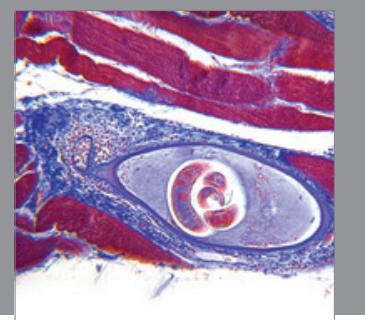

Gastroenterology

Research and Practice
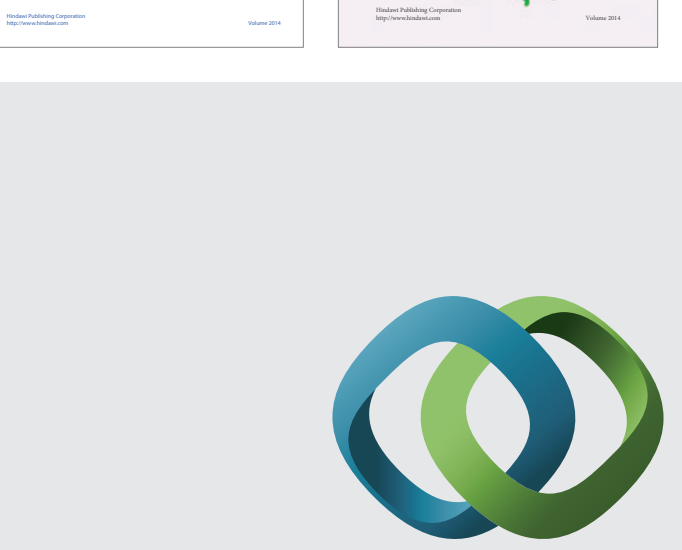

\section{Hindawi}

Submit your manuscripts at

http://www.hindawi.com
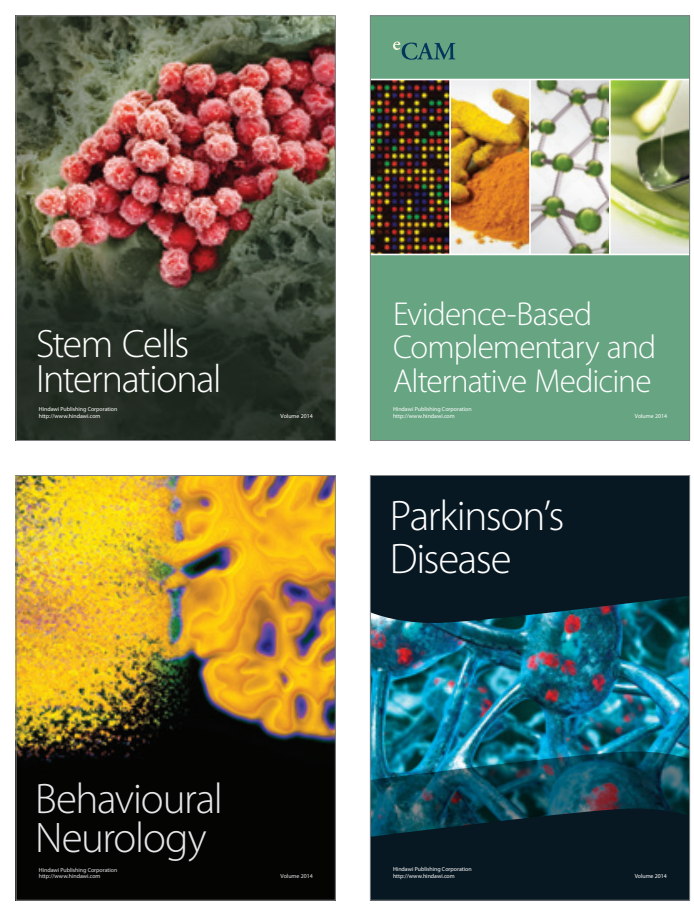

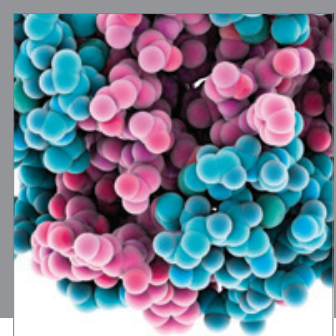

Journal of
Diabetes Research

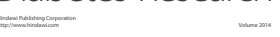

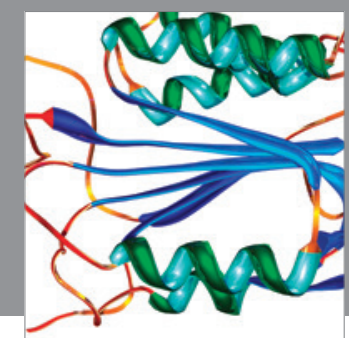

Disease Markers
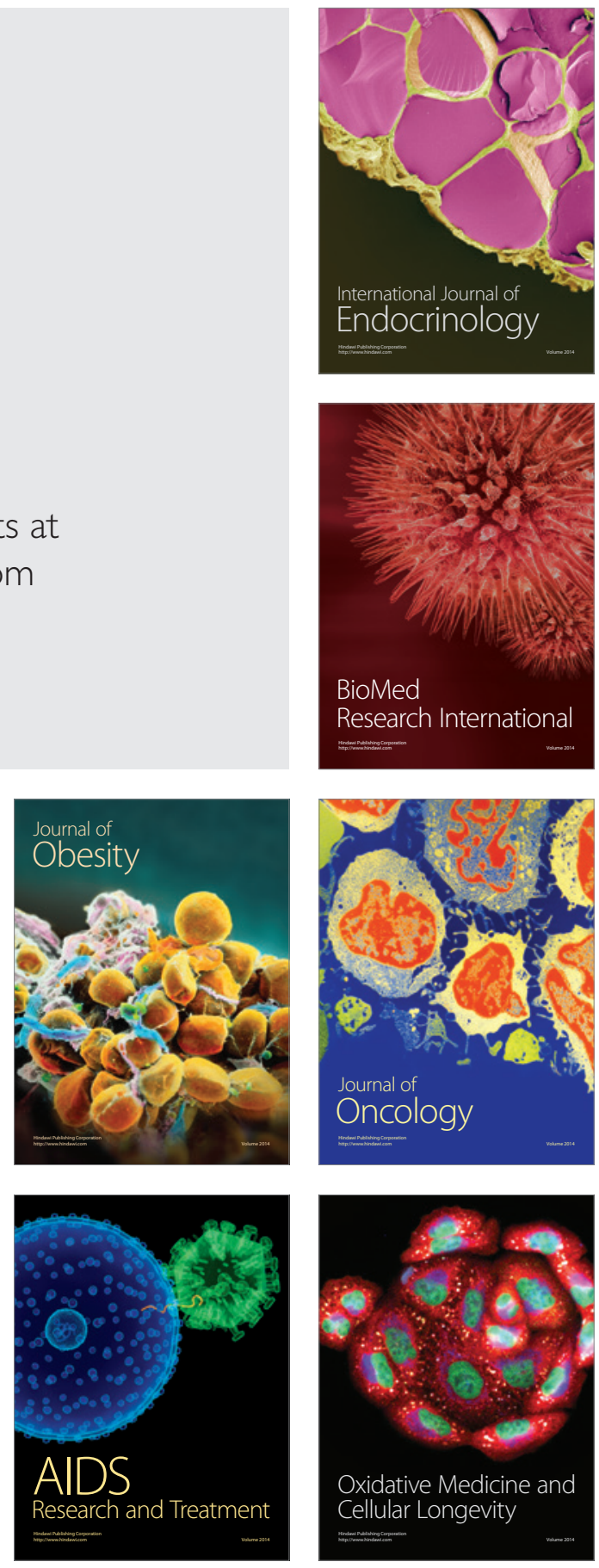